\title{
NECESSIDADES (DE SAÚDE) DE ADOLESCENTES DO D.A. RAPOSO TAVARES, SP, REFERIDAS À FAMILIA, ESCOLA E BAIRRO
}

\author{
ADOLESCENT'S (HEALTH) NEEDS REFERRING TO FAMILY, SCHOOL \\ AND NEIGHBORHOOD
}

SOARES, C. B.; ÁVILA, L. K. d.; SALVETTI, M. d. G. Necessidades (de saúde) de adolescentes do D.A. Raposo Tavares, SP, referidas à família, escola e bairro. Rev. Bras. Cresc. Desenv. Hum., 10 (2), 2000.

Resumo: Este estudo, de natureza epidemiológica descritiva, objetiva caracterizar as necessidades de saúde dos adolescentes do Distrito Administrativo Raposo Tavares - município de São Paulo, que apresenta diversas situações de vulnerabilidade social. Foram estudados 133 adolescentes e suas famílias, inscritos em 12 escolas públicas e I Centro de Juventude, buscando localizar as suas necessidades de saúde a partir das suas formas de inserção social (plenamente incluidos, precariamente incluidos e excluidos). Os resultados indicam que às formas de reprodução evidenciadas na amostra estudada se associavam necessidades diferenciados, seja do ponto de vista quantitativo, seja do ponto de vista qualitativo, relacionadas às agências e ao espaço de socialização: família, escola e bairro. São necessárias ações intersetoriais, não só de incremento das políticas sociais públicas, mas de capacitação dos adolescentes para que exerçam seus direitos sociais e possam dispor de processos de socialização acolhedores e protetores.

Palavras-chave: adolescentes; necessidades de saúde; farnilia; escola; bairro, grupos sociais homogéneos.

1 Prof Dr. Depto. Enfermagem em Saúde Coletiva, Escola de Enfermagem da USP, Av. Dr. Enéas de Carvalho Aguiar, 419, 05403-000 - São Paulo- SP.

2 Aluna de Graduação em Enfermagem e Bolsista de iniciação Cientifica da FAPESP (Proc. 97/11862-9), à época da elaboração do trabalho. Enfermeira do Hospital Dom Silvério Gomes Pimenta. Mestranda na área de Enfermagem em Saúde Coletiva da Escola de Enfermagem da USP. Escola de Enfermagem da USP. Av. Dr. Enéas de Carvalho Aguiar, 419, CEP 05403-000 - São Paulo - SP.

3 Aluna de Graduação em Enfermagem e Bolsista de iniciação Cientifica da FAPESP (Proc. 97/11860-6), à época da elaboração do trabalho. Enfermeira do Hospital do Câncer. Rua Prof. Antônio Prudente, 211 - Liberdade, CEP 01509-900.

Local de realização do trabalho: Departamento de Enfermagem em Saúde Coletiva, Escola de Enfermagem - USP. Autor responsável para troca de correspondência: Cássia Baldini Soares.

Este trabalho congrega parte dos resultados do projeto matriz a que está vinculado, financiado pela FAPESP (Auxílio Pesquisa - Proc. FAPESP n 97/11861-2). Faz parte do Projeto integrado de Pesquisa que recebeu auxílio financeiro da Pró Reitoria de Pesquisa da Universidade de São Paulo - projeto PII, no ano de 1998 e projeto PI, no ano de 1999.

Este trabalho foi apresentado no $51^{\circ}$ Congresso Brasileiro de Enfermagem e $10^{\circ}$ Congresso Pan-americano de Enfermagem, realizado em Florianópolis - SC, no período de 7 a 12 de outubro de 1999, com o Titulo: Necessidades de saúde de adolescentes de um distrito da cidade de São Paulo. 


\section{INTRODUÇÃO}

O objeto deste estudo diz respeito às necessidades de saúde de adolescentes de um Distrito Administrativo do Município de São Paulo o D. A. Raposo Tavares ${ }^{4}$, tomado como referência pois apresenta algumas condições agravadas de vulnerabilidade social para os adolescentes que lá trabalham, vivem e estudam (SOARES, ÁVILA \& SALVETTI, 1998).

Apesar da escassez de estudos epidemiológicos que tomam as necessidades de saúde do adolescente como objeto, sabemos que os problemas de saúde do adolescente vêm sendo cada vez menos tratados como síndrome biológica da puberdade, e, gradualmente, orientados pela interdisciplinaridade, como uma primeira fase da juventude (MWSS, 1976) 5 . Os resultados de estudos no campo da sociologia têm permitido um diálogo profícuo com as preocupações diante das quais se colocam aqueles que tratam o tema sob a perspectiva da saúde coletiva que tem se valido da interdisciplinaridade para estudar o seu objeto.

Assim, acredita-se que os problemas relacionados a processos de socialização incompletos (ADORNO, 1991), que vulnerabilizam os adolescentes (AYRES, 1996), podem determinar necessidades de saúde bastante diferenciados de acordo com sua inserção social. Dizem respeito a dificuldades da família em atingir padrões mínimos de reprodução social, determinando, muitas vezes: a inserção precoce do adolescente no trabalho; a evasão e o atraso escolar; a gravidez precoce; a vivência na rua e experiências de proximidade com atividades delinqüenciais e uso de drogas (ADORNO, 1991). Contemporaneamente, não se pode negar que a exposição dos jovens ao tráfico e ao consumo de drogas requer uma atenção especial na aquilatação do conjunto de necessidades deste grupo (ZALUAR, 1996). Acresce que as drogas e a violência são as principais preocupações das instituições sociais da região estudada - especialmente das escolas públicas -, no que se refere ao entorno social mais próximo dos adolescentes. Os equipamentos de saúde da região não desenvolvem programas específicos para adolescentes ${ }^{6}$ (SOARES, ÁVILA \& SALVETTI, 1998).

Diante da finalidade deste estudo - desenhar projetos de intervenção na região, particularizando necessidades relacionadas às drogas, à sexualidade e à Aids ${ }^{7}$ - partimos do entendimento que para se organizar as ações de saúde, deve-se considerar não somente as necessidades de saúde, mas também o contexto instaurador dessas necessidades, resgatando-os a partir da vida cotidiana dos adolescentes sem reduzí-los a processos fisiopatológicos (SCHRAIBER \& MENDESGONÇALVES, 1996). Também como recomendam AYRES \& JUNIOR (1996), acreditamos que os programas de atenção à saúde do adolescente devam fazer a ausculta das necessidades de saúde, espaço de voz ativa dos adolescentes na explicitação dessas necessidades.

Diante dessas considerações, este trabalho - um estudo epidemiológico descritivo - teve por objetivo caracterizar as necessidades de saúde dos adolescentes a partir da ética dos próprios adolescentes na região em foco, considerada a inserção social de suas famílias. Como tal, se inscreve no conjunto de estudos voltados para o nível local de saúde na perspectiva do monitoramento estratégico da saúde do coletivo (BREILH, 1994).

\section{SAUDE COLETIVA, NECESSIDADES DE SAÚDE E PROCESSOS DE SOCIALIZAÇÃO}

O conceito de necessidades de saúde vem sendo tratado pelas diferentes abordagens das quais se servem as ciências sociais aplicadas à saúde. Necessidades de saúde estão, quase sempre, referidas à assistência, representadas na procura de cuidados médicos e na oferta de serviços de saúde SCHRAIBER \& MENDES GONÇALVES,1996). De acordo com STOTZ (1991), esse entendimento diz respeito à maneira com que, inicial e majoritariamente, a saúde pública foi se apropriando do problema, a partir

4 O Distrito Administrativo de Raposo Tavares faz parte de um conjunto de 6 Distritos que compõem a área de abrangência do Hospital Universitário - Universidade de São Paulo

5 Veja-se, por exemplo, a coletânea da Comissão Nacionai de População e Desenvolvimento (CNPD. 1998), que reúne, para dar tratamento à questão do jovem, artigos relativos a aspectos: sócio-demográficos, de saúde, de educação, trabalho, previdência e cultura, para dar subsidios para a elaboração de políticas públicas voltadas para a juventude.

6 De acordo com informações da Secretaria Municipal da Saúde, a região é servida basicamente por quatro unidades de saúde: PAS Jd. Boa Vista, PAS Jd. Paulo Vl, PAS Vila Borges e PAS São Jorge. Dessas, apenas o PAS Jardhn Paulo Vl deu inicio a um programa educativo para adolescentes em 1999

7 Esses têm sido, sem dúvida, os principais temas que preocupam os especialistas em prevenção. Veja-se entre outros, a coletânea construída para orientar a prevenção nas escolas públicas estaduais de São Paulo do FDE/SP (AMARO et al., 1996). 
da integração entre a antropologia e a sociologia funcionalista.

No nosso entendimento, a abordagem das necessidades de saúde deve tomar como referência a saúde-doença como processo social, ou seja, partir da compreensão de que as raízes dos problemas de saúde - e, portanto, das necessidades de saúde - estariam diretamente relacionadas à reprodução da vida social. As formas de trabalhar e de viver dos diferentes grupos sociais determinariam potenciais de desgaste e de fortalecimento diferentes para os diferentes grupos ou classes sociais e portanto diferentes necessidades de saúde (BREILH \& GRANDA, 1989; LAURELL, 1989; BREILH, 1994; FACCHINI, 1995; QUEIROZ \& SALUM, 1997).

De acordo com CAMPANA (1997, p. 1456), “a família e a escola são duas instâncias formalizadoras de mediações que operam em volta da criança [e do adolescente] e da intimidade familiar.(...) cumprem igualmente, de uma ou de outra forma, seu papel transmissor de socialização, seja para alienar ou elevar a consciência e a solidariedade humana”, tendo, em suma, uma ação que protege ou deteriora esses atributos e as relações humanas. Mas, os adolescentes encontram também a extensão de seu processo de socialização no bairro: nos espaços entre a casa e a escola, nas áreas de lazer, na vizinhança, nos pontos de encontro.

Assim sendo, os adolescentes têm necessidades de saúde que são, de um lado, concernentes à fase da vida pela qual transitam, e que sofrem as inflexões próprias do grupo social em que suas famílias se inscrevem, o que torna particular e relevante o estudo sobre a heterogeneidade dos problemas que enfrentam (SOARES, 1997). De outro lado, a transmissão da cultura dominante contemporânea, com suas prescrições de valores do que é ser um jovem-adolescente que perpassa as barreiras de classe e se espalha por todos os espaços da cidade, mediada pelas agências e espaços de socialização norteará a busca de uma identidade, a formação da personalidade e o advento de novas necessidades ${ }^{8}$. Nessa busca, os adolescentes sofreriam o impacto da estrutura familiar e da inserção social de suas famílias (traduzidas pela forma de se reproduzir socialmente sob o modo de produção capitalista), o que determinaria diferentes formas particulares de vivenciar a adolescência.

\section{PERCURSO METODOLÓGICO}

Neste trabalho, empreendemos o percurso metodológico recomendado de QUEIROZ \& SALUM (1997) que propõem uma base operacional que pré-define três grupos sociais homogêneos (GSHs) a partir das possibilidades e limites de reprodução social das famílias: o GSHI incluidos na vida social, o GSH2 precariamente incluídos na vida social, e o GSH3 - excluídos da vida social, denominação adotada por SALUM (2000) a partir das indicações de POCHMANN (1999). Assim, a classificação da inserção social dos adolescentes aqui pesquisados foi feita a partir da caracterização das formas de reprodução social das suas famílias.

3.1 População de estudo: a população de estudo foi constituída pela totalidade dos adolescentes escolares moradores no D.A. Raposo Tavares (7.449 adolescentes de 12 a 18 anos incompletos) (FUNDAÇÃ O IBGE, 1998).

3.2 Amostra estudada: a amostra foi constituída por adolescentes inscritos em instituições de ensino da região e estabelecida por critérios de estratificação por idade. Foi estimada para ser representativa do conjunto de adolescentes ( 12 a 18 anos incompletos) estudantes das escolas públicas da região, obedecendo à proporcionalidade do número de alunos nessa faixa etária matriculados em cada unidade. Um levantamento inicial, realizado a partir de consulta aos bancos de dados da Secretaria Municipal e da Secretaria Estadual da Educação e da Promoção Social, mostrou que havia 12 escolas públicas ( 4 estaduais de $1^{\circ} \mathrm{e}$ $2^{\circ}$ graus e 8 municipais de $1^{\circ}$ grau) e um único Centro de Juventude no distrito. Para viabilizar a estratégia de coletar dados através de uma abordagem inicial dos adolescentes em grupos focais, a amostra foi dividida em vinte grupos de 8 alunos (160), proporcionalmente divididos por todas as unidades de ensino. A partir da lista dos alunos matriculados, foi realizado um sorteio aleatório. Houve retorno de 146 questionários familiares, com uma perda de 8,75\% acrescida de uma segunda perda $(8,1 \%$ dos questionários não estavam completamente preenchidos). É possível que as famílias mais próximas da definição de excluídas tenham tido maiores dificuldades em preencher o questionário. Por isso é que os resultados se referem a 133 adolescentes (47,4\% do sexo

8 Um exemplo dessas determinações e influências pode ser analisado a partir da dimensão que assume a inserção precoce dos adolescentes no trabalho. Estudos sobre o trabalho do adolescente em São Paulo revelam que: uma parte expressiva de adolescentes se insere no mundo do trabalho para ajudar na renda familiar (CERVINI \& BURGER, 1991; FUNDAÇÃO SEADE, 1993). Para outra parcela, no entanto, está também em jogo, a necessidade de consumir símbolos de identidade jovem (MADEIRA, 1986). 
masculino e $52,6 \%$ do sexo feminino) e suas famílias.

3.3 Instrumentos de coleta de dados: A coleta dos dados foi realizada através de um formulário e um questionário (WITT, 1973). O contato inicial com os adolescentes realizou-se nas escolas, em sala de aula, valendo-se da técnica de grupo focal, ocasião em que, ao introduzir e especificar o objetivo e a finalidade da pesquisa, discutiu-se os dados sociais do distrito a partir dos resultados obtidas nos estudos de SPOSATI (1996 e s/d). Ao final de cada grupo focal, o formulário foi aplicado individualmente e preenchido sob a supervisão de uma monitora: entre questões abertas e fechadas, tratava dos aspectos relacionados às necessidades de saúde dos adolescentes, tomando como referência as agências e instâncias de socialização: família, escola e bairro, seus aspectos positivos, negativos e suas carências. Através do formulário recolheram-se ainda informações sobre as formas de lazer dos adolescentes, e, particularmente, sobre sua experiências de orientação sobre drogas, sexualidade e AIDs ${ }^{9}$. O questionario referido às formas de trabalhar e de viver das famílias ${ }^{10}$ dos adolescentes, foi preenchido pela família com instruções para o retorno à escola, dele constando questões fechadas, previamente codificadas.

3.4 Trabalho de campo: A coleta de dados junto às escolas foi realizada nos meses de set/out/nov/dez/98 e, junto ao Centro de Juventude, nos meses de fev/mar/99, com autorização prévia dos órgãos competentes. Contatadas as instituições para agendar o sorteio e a entrevista em grupo com os adolescentes, estas se responsabilizaram pelos procedimentos administrativos concernentes à participação na pesquisa. Não obstante, todos os adolescentes foram consultados pela equipe de pesquisadores sobre sua vontade de participar da pesquisa.

3.5 Sistematização e análise das informações: As informações foram registradas em banco de dados e processadas num programa em Dbase, especialmente projetado para construir os GSHs ${ }^{11}$. As respostas às questões abertas do formulário aplicado entre os adolescentes foram reagrupadas de modo a expressar genericamente as opiniões dos entrevistados acerca do que era positivo, negativo ou passível de mudança. Os dados foram submetidos à análise em SPSS (teste de associação Qui-quadrado) e EPI-info-6 (teste de diferença de proporções), valendo-se do nível de 5\% para ajuizar a significância estatística. Os resultados foram analisados de acordo com as referências pelas quais foram obtidas - as agências de socialização, família e escola, e o espaço de socialização, bairro - estratificandoos, a partir da caracterização da inserção social das famílias nos diferentes GSHs evidenciados na amostra estudada.

\section{RESULTADOS}

4.1 A família: A distribuição das famílias dos adolescentes estudados nos grupos sociais prédefinidos metodologicamente era a seguinte: 1 $6,5 \%$ da amostra estudada congregava famílias do GSH 1 - plenamente incluidos; S l, 1\% da amostra estudada congregava famílias do GSH 2 - precariamente incluidos - e 32,3\% da amostra estudada congregava famílias do GSH3 - excluídos sociais. Suas principais características estão descritas no Quadro l que expõe a distribuição das famílias de acordo com as variáveis de corte para formas de trabalhar e de viver.

No que se refere aos aspectos positivos da família, os dados da Tabela 1 chamam a atenção para o fato de que os adolescentes privilegiavam o amor, em freqüências apreciáveis, ainda que essa manifestação fosse mais expressiva entre os plenamente incluidos $(54,5 \%)$ em relação aos demais grupos (36,8\% nos precariamente incluídos e 39,5\%, nos excluídos). O diálogo dentro do âmbito familiar era um aspecto igualmente valorizado entre os grupos: a esse respeito, quando perguntados sobre com quem costumavam conversar sobre seus problemas, os plenamente in-

9 Consultamos o “Questionário Infantil do Estudo Epidemiológico”, produzido no Departamento de Medicina Social da Universidade Federal de Pelotas em pesquisa coordenada pelo Prof. Dr. Luis Augusto FACCHINI e, com sua devida autorização, apropriamonos de alguns dos seus encaminhamentos para formular o nosso instrumento.

10 Construido a partir do instrumento Condições de Saúde da População do Distrito Sanitário do Butantã - SP, do Departamento de Enfermagem em Saúde Coletiva da EEUSP, em pesquisa coordenada pela profa. Vilma M. de QUEIROZ e com sua devida autorização. O conjunto de indicadores/variáveis utilizados para fazer a releitura da categoria da reprodução social segue o esquema operacional proposto por QUEIROZ \& SALUM, 1997. Nesse esquema, as variáveis utilizadas para identificar as formas de trabalhar (renda familiar per capita, benefícios oriundos do trabalho; registro em carteira) são combinadas com aquelas utilizadas para identificar as formas de viver (propriedade da habitação, percepção de risco; participação social). A associação de tais indicadores, por fim, indica o pertencimento das famílias estudadas aos respectivos grupos sociais homogêneos.

11 KOGANEZAWA, E.; ORSINI, S. Um programa em D-BASE para classificar grupos sociais homogêneos. Escola de Enfermagem da USP, São Paulo, 1996. 
Quadro 1: Distribuição das famílias dos adolescentes estudados no D.A. Raposo Tavares, por GSH, de acordo com as variáveis de corte para formas de trabalhar e de viver, São Paulo, 1999*.

\begin{tabular}{|c|c|c|}
\hline $\begin{array}{c}\text { GSH1 } \\
\text { (22 famílias } 16,5 \% \text { da amostra) }\end{array}$ & $\begin{array}{c}\text { GSH2 } \\
\text { (68 famílias } 51,1 \% \text { da amostra) }\end{array}$ & $\begin{array}{c}\text { GSH3 } \\
\text { (43 famílias } 32,3 \% \text { da amostra) }\end{array}$ \\
\hline $\begin{array}{l}\text { Padrão de inserção na produção } \\
\text { - } \quad 81,8 \% \text { (18) das famílias } \\
\text { possuem RFPC acima de } 1,8 \mathrm{SM} \\
\text { p } \quad 100 \% \text { (22) das famílias } \\
\text { possuem entre os membros pelo } \\
\text { menos um dos trabalhadores com } \\
\text { registro em carteira } \\
\quad 50 \% \text { (11) das famílias } \\
\text { usufruem de } 2 \text { ou mais beneficios } \\
\text { oriundos do trabalho de seus } \\
\text { membros, inclusive assistência } \\
\text { médca }\end{array}$ & $\begin{array}{l}\text { Padrão de inserção na produção } \\
\text { possuem RFPC acima de } 1,8 \mathrm{SM} \\
\text { p } \quad 77,9 \% \text { (53) das famílias } \\
\text { possuem entre os membros pelo } \\
\text { menos um dos trabalhadores com } \\
\text { registro em carteira } \\
\text { - } 22,1 \% \text { (15) das famílias } \\
\text { usufruem de } 2 \text { ou mais beneficios } \\
\text { oriundos do trabalho de seus } \\
\text { membros, inclusive assistência } \\
\text { médca }\end{array}$ & $\begin{array}{l}\text { Padrão de inserção na produção } \\
\text { - } \quad 9,3 \% \text { (4) das familias } \\
\text { possuem RFPC acima de } 1,8 \mathrm{SM} \\
\text { - } \quad 55,8 \% \text { (24) das familias } \\
\text { possuem entre os membros pelo } \\
\text { menos um dos trabalhadores com } \\
\text { registro em carteira } \\
\quad 2,3 \% \text { (1) das famílias } \\
\text { usufruem de } 2 \text { ou mais beneficios } \\
\text { oriundos do trabalho de seus } \\
\text { membros, inclusive assistência } \\
\text { médca }\end{array}$ \\
\hline $\begin{array}{l}\text { Padrão de inserção no consumo } \\
\text { p } \quad 95,5 \% \text { (21) das familias são } \\
\text { proprietárias de suas moradias } \\
\text { p } \quad 77,3 \% \text { (17) das famílias } \\
\text { possuem entre seus membros pelo } \\
\text { menos um que participa de algum } \\
\text { tipo de vida associativa } \\
\text { - } \quad 50 \% \text { (11) das familias se } \\
\text { sentem expostas a algum tipo de } \\
\text { risco }\end{array}$ & $\begin{array}{l}\text { Padrão de inserção no consumo } \\
\text { - } \quad 64,7 \% \text { ( } 44 \text { ) das famílias são } \\
\text { proprietárias de suas moradias } \\
\text { p } 54,4 \% \text { (37) das famílias } \\
\text { possuem entre seus membros pelo } \\
\text { menos um que participa de algum } \\
\text { tipo de vida associativa } \\
\text { - } 73,5 \% \text { ( } 50 \text { ) das famílias se } \\
\text { sentem expostas a algum tipo de } \\
\text { risco }\end{array}$ & $\begin{array}{l}\text { Padrão de inserção no consumo } \\
\text { - } \quad 51,2 \% \text { ( } 22) \text { das familias são } \\
\text { proprietárias de suas moradias } \\
\text { - } \quad 25,6 \%(11) \text { das famílias } \\
\text { possuem entre seus membros pelo } \\
\text { menos um que participa de algum } \\
\text { tipo de vida associativa } \\
\text { - } \quad 90,7 \%(39) \text { das famílias se } \\
\text { sentem expostas a algum tipo de } \\
\text { risco }\end{array}$ \\
\hline
\end{tabular}

* Todos os dados estratificados deste quadro foram analisados por testes de significancia $(p=0,05)$, apresentando sempre diferenças estatísticas significantes, o que era esperado uma vez que se tratavam de variáveis de corte na determinação do pertencimento ao grupo correspondente.

cluídos apontavam a mãe em primeiro lugar (45,5\%), sendo que os adolescentes pertencentes aos demais grupos tendiam a indicar a mãe em segundo lugar (23,5\% nos precariamente incluidos e 32,6\%, nos excluídos). E possível observar ainda que eram os excluídos os que tendiam a destacar em maior freqüência o papel positivo de um membro da família em especial ( $9,3 \%)$, contra nenhuma menção ao fato, nos plenamente incluídos, e uma freqüência menor de referências nos precariamente incluídos (5,9\%).

Em todos os grupos, as brigas e os comportamentos agressivos - diversas formas de agressividade e violência doméstica - foram apontados como 0 aspecto mais negativo da família, mas ainda assim os excluidos tendiam a ocupar lugar de destaque (53,5\%), e os precariamente incluídos eram os que afirmavam menos se ressentir dessas condições (36,8\%). Nesse sentido, reportando-se aos dados apresentados no Gráfico 1 - formas de punição adoradas pelas famílias quando o adolescente se comporta de forma recriminável verifica-se que a conversa era tanto mais freqüente quanto mais aumentava o grau de inclusão social ( $p$ = 0,076477); ao contrário, embora não significante do ponto de vista estatístico, a repreensão severa e a punição corporal prevaleciam tendencialmente em maiores freqüencias a medida que aumentavam os graus de exclusão social.

Em relação às carências sentidas na família (Tabela 1), chama a atenção o fato de que, embora quase 1/3 do total dos adolescentes pesquisados se ressentisse da falta da presença de familiares, essa queixa aparecia de maneira mais marcante no grupo dos excluidos, embora os testes não tenham apontado diferença significante. De outro lado, foram os plenamente incluidos aqueles que mais referiram não sentir falta de nada no espaço doméstico, em freqüências significantemente mais elevadas $(p=0,040599)$ que nos demais grupos.

A Tabela 2 expõe os dados referentes às formas de lazer dos adolescentes, ampliando o espectro de positividades, negatividades e carências. Ainda que a prática de esportes tenha sido referida em primeiro lugar pela grande maioria dos adolescentes pesquisados, as porcentagens 


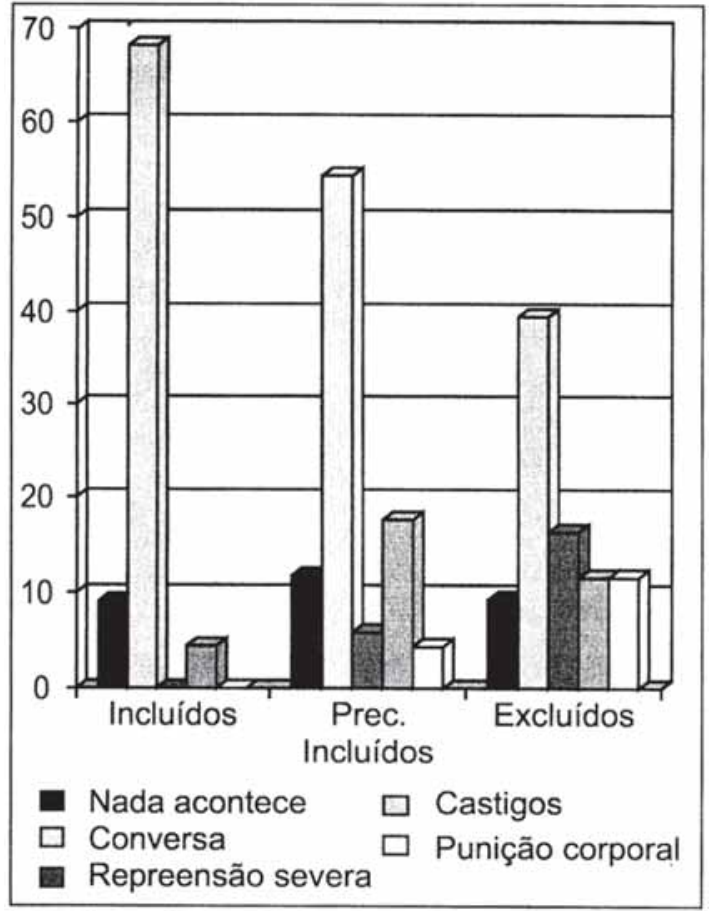

Gráfico 1: Distribuição dos adolescentes estudados do D.A. Raposo Tavares, por grupo social homogêneo, segundo formas de punição adotadas pela farnilia, São Paulo, 1999 mais elevadas provinham dosplenamente incluidos, indicando uma tendência. Essa preponderancia não se restringia somente a essa modalidade: eram eles que mais passeavam, iam a bailes e festas, viam vídeo, visitavam e recebiam amigos, iam ao cinema, participavam de atividades religiosas, iam ao fliperama e até mesmo os que mais viam TV ou brincavam. De outro lado, entre os excluidos era alta a porcentagem daqueles que namoravam, resultando em diferença estatisticarnente significante $(\mathrm{p}=0,02782)$.

4.2 A escola: A Tabela 3 expõe os dados relativos à escola. Nela, pode-se observar que a escola era positivada pelos adolescentes pesquisados por referência às atividades de lazer desenvolvidas no seu âmbito e à amizade, especialmente freqüentes entre os precariamente incluídos e excluidos. Se somarmos as frequências relativas a esses elementos, observaremos que elas representavam um percentual (36,5\% nos plenamente incluídos, 45,6\%, nos precariamente incluídos e 46,5\%, nos excluídos), praticamente três vezes maior do que o percentual referente à categoria mais propriamente atinente aos objetivos da escola: o ensino propriamente dito $(4,5 \%$ nos plenamente incluídos, 14,7\%, nos precariamente incluídos e 16,3\%, nos excluídos).

Quando chamados a apontar os aspectos negativos da escola (Tabela 3), os adolescentes

Tabela 1: Distribuição dos adolescentes estudados do D.A. Raposo Tavares, por GSH, segundo suas opiniões a respeito da família, São Paulo, 1999.

\begin{tabular}{lrrrrrrrr}
\hline \multicolumn{1}{c}{ GSH } & \multicolumn{2}{c}{$\begin{array}{c}\text { Plenamente } \\
\text { incluídos }\end{array}$} & \multicolumn{2}{c}{$\begin{array}{c}\text { Precariamente } \\
\text { incluídos }\end{array}$} & \multicolumn{2}{c}{$\begin{array}{c}\text { Excluídos } \\
\text { sociais }\end{array}$} & \multicolumn{2}{c}{ Total } \\
\hline \multicolumn{1}{c}{ Opiniões sobre a família } & \multicolumn{1}{c}{$\mathbf{n}$} & \multicolumn{1}{c}{$\%$} & \multicolumn{1}{c}{$\mathbf{n}$} & \multicolumn{1}{c}{$\%$} & \multicolumn{1}{c}{$\mathbf{n}$} & \multicolumn{1}{c}{$\%$} & $\mathbf{n}$ & \multicolumn{1}{c}{$\%$} \\
\hline \multicolumn{1}{c}{ Total } & 22 & 100,0 & 68 & 100,0 & 43 & 100,0 & 133 & 100,0 \\
\hline \multicolumn{1}{c}{ Aspectos positivos } & & & & & & & & \\
Amor & 12 & 54,5 & 25 & 36,8 & 17 & 39,5 & 54 & 40,6 \\
Diálogo & 05 & 22,7 & 16 & 23,5 & 10 & 23,3 & 31 & 23,3 \\
Familiares & 0 & 0,0 & 04 & 5,9 & 04 & 9,3 & 08 & 6,0 \\
Outros & 04 & 18,2 & 19 & 28,0 & 07 & 16,3 & 30 & 22,5 \\
Em branco & 01 & 4,5 & 04 & 5,9 & 05 & 11,6 & 10 & 7,5 \\
$\quad$ Aspectos negativos & & & & & & & & \\
Brigas/ Comportamentos agressivos & 10 & 45,4 & 25 & 36,8 & 23 & 53,5 & 58 & 43,6 \\
Separação/Abandono & 02 & 9,0 & 08 & 11,8 & 05 & 11,7 & 15 & 11,8 \\
Outros & 09 & 40,9 & 23 & 33,9 & 10 & 23,2 & 42 & 31,6 \\
Em branco & 02 & 9,1 & 12 & 17,6 & 05 & 11,6 & 19 & 14,3 \\
& & & & & & & & \\
Nada Carências & 10 & 45,5 & 26 & 38,2 & 08 & 18,6 & 44 & 33,1 \\
Familiares & 06 & 27,3 & 16 & 23,5 & 15 & 34,9 & 37 & 27,8 \\
Companheirismo & 04 & 18,2 & 14 & 20,6 & 10 & 23,3 & 28 & 21,0 \\
Outros & 02 & 9,1 & 05 & 7,4 & 04 & 9,3 & 11 & 8,3 \\
Em branco & 0 & 0,0 & 07 & 10,3 & 06 & 14,0 & 13 & 9,8 \\
\hline
\end{tabular}


Tabela 2: Distribuição dos adolescentes estudados do D.A. Raposo Tavares, por GSH, segundo as atividades de lazer que realizam, São Paulo, 1999.

\begin{tabular}{lcccccccc}
\hline \multicolumn{1}{c}{ GSH } & \multicolumn{2}{c}{$\begin{array}{c}\text { Plenamente } \\
\text { incluídos }\end{array}$} & \multicolumn{2}{c}{$\begin{array}{c}\text { Precariamente } \\
\text { incluídos }\end{array}$} & \multicolumn{2}{c}{$\begin{array}{c}\text { Excluídos } \\
\text { sociais }\end{array}$} & \multicolumn{2}{c}{ Total } \\
\hline \multicolumn{1}{c}{ Atividades de lazer } & $\mathbf{n}$ & $\%$ & $\mathbf{n}$ & $\%$ & $\mathbf{n}$ & $\%$ & $\mathbf{n}$ & $\%$ \\
\hline Praticar esportes & 18 & 81,8 & 42 & 61,7 & 26 & 60,4 & 86 & 64,7 \\
Namorar/ Ficar & 14 & 63,6 & 35 & 51,5 & 33 & 76,7 & 82 & 61,7 \\
Ir a festas e bailes & 16 & 72,7 & 37 & 54,4 & 25 & 58,1 & 78 & 58,6 \\
Passear & 16 & 72,7 & 39 & 57,4 & 22 & 51,6 & 77 & 57,9 \\
Ver televisão & 14 & 63,6 & 37 & 54,4 & 23 & 53,5 & 74 & 55,6 \\
Viajar & 13 & 59,1 & 38 & 55,9 & 23 & 53,5 & 74 & 55,6 \\
Ver vídeos & 15 & 68,2 & 35 & 51,5 & 21 & 48,8 & 71 & 53,4 \\
Visitar/ receber amigos & 13 & 59,1 & 29 & 42,6 & 20 & 46,5 & 62 & 46,6 \\
Ir ao cinema & 11 & 50,0 & 21 & 30,9 & 20 & 46,5 & 52 & 39,1 \\
Brincar & 10 & 45,5 & 22 & 32,4 & 16 & 37,2 & 48 & 36,1 \\
Participar em atividades religiosas & 11 & 50,0 & 24 & 35,3 & 11 & 25,6 & 46 & 34,6 \\
Ir ao futebol & 08 & 36,4 & 18 & 26,5 & 16 & 37,2 & 42 & 31,6 \\
Dormir & 06 & 27,3 & 18 & 26,5 & 12 & 27,9 & 36 & 27,1 \\
Ir ao Fliperama & 07 & 31,8 & 18 & 26,5 & 05 & 11,6 & 30 & 22,5 \\
Outros & 03 & 13,6 & 13 & 19,1 & 06 & 13,9 & 24 & 18,0 \\
\hline
\end{tabular}

Tabela 3: Distribuição dos adolescentes estudados do D.A. Raposo Tavares, por GSH, segundo sua opinião a respeito da escola que freqüentam, São Paulo, 1999.

\begin{tabular}{|c|c|c|c|c|c|c|c|c|}
\hline \multirow{2}{*}{$\begin{array}{c}\text { GSH } \\
\text { Opiniões sobre a escola }\end{array}$} & \multicolumn{2}{|c|}{$\begin{array}{c}\text { Plenamente } \\
\text { incluídos }\end{array}$} & \multicolumn{2}{|c|}{$\begin{array}{c}\text { Precariamente } \\
\text { incluídos }\end{array}$} & \multicolumn{2}{|c|}{$\begin{array}{l}\text { Excluídos } \\
\text { sociais }\end{array}$} & \multicolumn{2}{|c|}{ Total } \\
\hline & $\mathbf{n}$ & $\%$ & $\mathbf{n}$ & $\%$ & $\mathbf{n}$ & $\%$ & $\mathbf{n}$ & $\%$ \\
\hline Total & 22 & 100,0 & 68 & 100,0 & 43 & 100,0 & 133 & 100,0 \\
\hline \multicolumn{9}{|l|}{ Aspectos positivos } \\
\hline Esporte/Lazer & 06 & 27,3 & 16 & 23,5 & 13 & 30,2 & 35 & 26,3 \\
\hline Recursos humanos e materiais & 05 & 22,7 & 17 & 25,0 & 08 & 18,6 & 30 & 22,5 \\
\hline Amizade & 02 & 9,1 & 15 & 22,1 & 08 & 16,3 & 25 & 18,8 \\
\hline Ensino & 01 & 4,5 & 10 & 14,7 & 07 & 16,3 & 18 & 13,5 \\
\hline Nada & 01 & 4,5 & 04 & 5,9 & 04 & 9,3 & 09 & 6,8 \\
\hline Em branco & 05 & 22,7 & 06 & 8,8 & 02 & 4,7 & 13 & 9,8 \\
\hline \multicolumn{9}{|l|}{ Aspectos negativos } \\
\hline Recursos humanos e materiais & 08 & 36,4 & 28 & 41,2 & 21 & 48,8 & 57 & 42,8 \\
\hline Violência/Drogas & 08 & 36,4 & 24 & 35,3 & 14 & 32,5 & 46 & 34,6 \\
\hline Outros & 03 & 13,6 & 05 & 20,6 & 05 & 11,6 & 13 & 9,8 \\
\hline Em branco & 03 & 13,6 & 11 & 16,2 & 03 & 7,0 & 17 & 12,8 \\
\hline \multicolumn{9}{|l|}{ Carências } \\
\hline Esporte/ Lazer & 12 & 54,5 & 19 & 27,9 & 10 & 23,3 & 41 & 30,8 \\
\hline Informática & 03 & 13,6 & 16 & 23,5 & 08 & 18,6 & 27 & 20,3 \\
\hline Artes/ Artesanato & 01 & 4,5 & 08 & 11,8 & 08 & 18,6 & 17 & 12,8 \\
\hline Outros & 03 & 13,6 & 10 & 14,7 & 04 & 9,3 & 17 & 12,8 \\
\hline Em branco & 03 & 13,6 & 15 & 22,1 & 13 & 30,2 & 31 & 23,3 \\
\hline
\end{tabular}


denunciaram as condições e recursos humanos/ materiais, em percentagens que aumentavam gradativarnente - embora estatisticamente não significamte - a medida que aumentava a exclusão social. A violência foi também denunciada pelos adolescentes de todos os grupos, muito discretamente mais freqüente à medida que aumentava o grau de inclusão social.

Finalmente, quando indagados sobre as carências da escola (Tabela 3), os esportes - somados às atividades de lazer - foram apontados destacadamente $(\mathrm{p}=0,026978)$ pelos adolescentes do grupo dos plenamente incluídos (54,5\%), em relação aos dos demais grupos $(27,9 \%$ nos precariamente incluídos e 23,3\% nos excluídos). A informática é um ensino requerido principalmente pelos precariamente incluídos, nesse caso, muito próximo da requisição de prática de esporte $(23,5 \%)$.

4.3 O bairro: Na Tabela 4 estão relacionadas as opiniões que os adolescentes tinham sobre o bairro em que moravam. A amizade ocupava lugar de destaque entre os aspectos positivos, em todos os grupos, seguida pelo lazer que tendia a prevalecer entre os exclídos quando comparados aos demais. Destaque-se que uma freqüência de $18,6 \%$ de adolescentes desse grupo não percebia nada de positivo no bairro.
Entre os aspectos negativos do bairro, a violência foi a mais freqüentemente citada em todos os grupos, queixa relevante $(p=0,031690)$ entre os adolescentes do grupo dos excluídos (60,5\%, contra 35,6\% nos precariamente incluídos e 50,0\% nos plenamente incluídos). A convivência com o problema das drogas, ocupando o segundo lugar, incomodava mais os adolescentes dos grupos com algum grau de inclusão (22,7\%) entre os plenamente incluídos, 26,5\% entre os precariamente incluídos e 14,0\% entre os excluídos).

Finalmente, entre as carências do bairro, as atividades de lazer e a segurança foram as mais freqüentemente referidas em todos os grupos. Note-se porém que os adolescentes do grupo dos precariamente incluídos, que menos se ressentiam da falta de lazer e de segurança, eram os que mais destacavam a falta de amizades no bairro, como carência importante.

4.4 A família, a escola e o bairro e as orientações sobre drogas, sexualidade e Aids: Na Tabela 5, pode-se observar que a família e a escola eram os espaços privilegiados para a orientação sobre drogas: cerca de $80 \%$ dos adolescentes, em todos os grupos, referiram ter recebido orientação sobre drogas na família, embora a referência à orientação sobre drogas na escola não tenha sido tão homogênea entre

Tabela 4: Distribuição dos adolescentes estudados do D.A. Raposo Tavares, por GSH, segundo sua opinião a respeito do bairro que residem, São Paulo, 1999.

\begin{tabular}{|c|c|c|c|c|c|c|c|c|}
\hline \multirow{2}{*}{$\frac{\text { GSH }}{\text { Opinião sobre o bairro }}$} & \multicolumn{2}{|c|}{$\begin{array}{c}\text { Plenamente } \\
\text { incluídos }\end{array}$} & \multicolumn{2}{|c|}{$\begin{array}{c}\text { Precariamente } \\
\text { incluídos }\end{array}$} & \multicolumn{2}{|c|}{$\begin{array}{c}\text { Excluídos } \\
\text { sociais }\end{array}$} & \multicolumn{2}{|c|}{ Total } \\
\hline & $\mathbf{n}$ & $\%$ & $\mathbf{n}$ & $\%$ & & $\%$ & $\mathbf{n}$ & $\%$ \\
\hline Total & 22 & 100,0 & 68 & 100,0 & 43 & 100,0 & 133 & 100,0 \\
\hline \multicolumn{9}{|l|}{ Aspectos positivos } \\
\hline Amigos & 07 & 31,8 & 18 & 26,5 & 13 & 30,2 & 38 & 28,6 \\
\hline Lazer & 03 & 13,6 & 16 & 23,5 & 12 & 27,9 & 31 & 23,3 \\
\hline Nada & 02 & 9,1 & 08 & 11,3 & 08 & 18,6 & 18 & 13,5 \\
\hline Outros & 07 & 31,8 & 16 & 23,6 & 04 & 9,3 & 17 & 12,8 \\
\hline Em branco & 03 & 13,6 & 10 & 14,7 & 06 & 14,0 & 19 & 14,3 \\
\hline \multicolumn{9}{|l|}{ Aspectos negativos } \\
\hline Violência & 11 & 50,0 & 32 & 35,6 & 26 & 60,5 & 69 & 51,9 \\
\hline Drogas & 05 & 22,7 & 18 & 26,5 & 06 & 14,0 & 29 & 21,8 \\
\hline Ambiente/ Infra estrutura & 04 & 18,2 & 04 & 5,9 & 04 & 9,3 & 12 & 9,0 \\
\hline Outros & 01 & 4,5 & 06 & 8,8 & 02 & 4,7 & 09 & 6,8 \\
\hline Em branco & 01 & 4,5 & 08 & 11,8 & 05 & 11,6 & 14 & 10,5 \\
\hline \multicolumn{9}{|l|}{ Carências } \\
\hline Lazer & 09 & 40,9 & 20 & 29,4 & 16 & 37,2 & 45 & 33,8 \\
\hline Segurança & 09 & 40,9 & 21 & 30,9 & 16 & 37,2 & 46 & 34,6 \\
\hline Amizade & 0 & 0,0 & 09 & 13,2 & 02 & 4,7 & 11 & 8,3 \\
\hline Nada & 01 & 4,5 & 06 & 8,8 & & 0,0 & 07 & 5,3 \\
\hline Outros & 02 & 9,0 & 04 & 5,9 & 06 & 14,0 & 12 & 9,0 \\
\hline Em branco & 01 & 4,5 & 08 & 11,8 & 03 & 7,0 & 12 & 9,0 \\
\hline
\end{tabular}


os grupos. A necessidade de obter orientações sobre drogas era tanto maior conforme se mergulhava na exclusão, sendo expressa por praticamente $50 \%$ dos adolescentes do grupo dos excluídos, e menos de $40 \%$ dos demais grupos, o que apenas se revela como tendência, uma vez que não foi observada diferença estatisticamente significante.

Os adolescentes que mais referiram receber orientação sobre sexualidade na família, eram os do grupo dos plenamente incluídos, seguidos dos excluídos e dos precariamente incluídos, em proporções diferentes e estatisticamente significantes $(p=0,003230)$. Eram eles que mais referiram ter recebido orientações sobre sexualidade na escola (82,3\%), embora em proporções não significantemente mais elevadas que nos demais grupos (72,7\% nos plenamente incluídos e $72,1 \%$ nos excluídos). Também eram os precariamente incluídos que, ao lado dos excluídos, mais sentiam necessidade de orientação sobre sexualidade (48,5\%, 44,2\%, respectivamente), contra apenas $13,6 \%$ dos plenamente incluídos, sendo que essa diferença foi estatisticamente significante $(p=0.013877)$.

Cerca de $70 \%$ dos adolescentes em todos os grupos referiram ter recebido orientação sobre Aids na família, muito embora as menores freqüências estivessem novamente localizadas entre os precariamente incluídos $(70,6 \%$, contra $86,4 \%$ nos plenamente incluídos e $81,4 \%$ nos excluídos). A orientação sobre Aids na escola foi majoritariamente referida entre eles, em freqüências discretamente mais elevadas que entre os demais. Tal como observamos em relação à necessidade de obter orientações sobre drogas, a necessidade de receber orientações sobre Aids era tanto mais significante quanto mais se mergulhava na exclusão, sendo expressa por mais de $50 \%$ dos adolescentes do grupo dos excluídos, tendo-se obtido um valor de $\mathrm{p}$, no entanto, pouco superior a $0,05(p=0.083619)$.

Tabela 5: Distribuição dos adolescentes estudados do D.A. Raposo Tavares, por GSH, de acordo com a situação de orientação sobre drogas, sexualidade e Aids. São Paulo, 1999.

\begin{tabular}{|c|c|c|c|c|c|c|c|c|}
\hline \multirow{2}{*}{$\begin{array}{c}\text { GSH } \\
\text { Orientações }\end{array}$} & \multicolumn{2}{|c|}{$\begin{array}{l}\text { Plenamente } \\
\text { incluídos }\end{array}$} & \multicolumn{2}{|c|}{$\begin{array}{c}\text { Precariamente } \\
\text { incluídos }\end{array}$} & \multicolumn{2}{|c|}{$\begin{array}{l}\text { Excluídos } \\
\text { sociais }\end{array}$} & \multicolumn{2}{|c|}{ Total } \\
\hline & $\mathbf{n}$ & $\%$ & $\mathbf{n}$ & $\%$ & $\mathbf{n}$ & $\%$ & $\mathbf{n}$ & $\%$ \\
\hline Total & 22 & 16,5 & 68 & 51,1 & 43 & 32,3 & 133 & 100,0 \\
\hline \multicolumn{9}{|c|}{ Orientações sobre drogas* } \\
\hline Família & 18 & 81,8 & 53 & 84,1 & 35 & 81,4 & 106 & 79,7 \\
\hline $\begin{array}{l}\text { Escola } \\
\text { Outros locais }\end{array}$ & 15 & 68,2 & 55 & 80,9 & 35 & 81,4 & 105 & 78,9 \\
\hline Outras instituições & 1 & 4,5 & 10 & 14,7 & 4 & 9,3 & 20 & 39,2 \\
\hline Amigos & 3 & 13,6 & & 5,9 & 2 & 4,7 & 10 & 19,6 \\
\hline $\begin{array}{l}\text { Necessidade de orientações } \\
\text { sobre drogas }\end{array}$ & 7 & 31,8 & 25 & 36,8 & 21 & 48,8 & 74 & 42,0 \\
\hline \multicolumn{9}{|c|}{ Orientações sobre sexualidade* } \\
\hline Família & 19 & 86,4 & 36 & 52,9 & 33 & 76,7 & 82 & 61,6 \\
\hline Escola & 16 & 72,7 & 56 & 82,3 & 31 & 72,1 & 103 & 77,4 \\
\hline \multicolumn{9}{|l|}{ Outros locais } \\
\hline Outras instituições & 3 & 13,6 & 11 & 16,2 & 5 & 11,6 & 19 & 14,3 \\
\hline Amigos & 3 & 13,6 & 5 & 7,4 & 2 & 4,7 & 10 & 7,5 \\
\hline $\begin{array}{l}\text { Necessidade de orientações } \\
\text { sobre sexualidade }\end{array}$ & 3 & 13,6 & 33 & 48,5 & 19 & 44,2 & 55 & 41,4 \\
\hline \multicolumn{9}{|l|}{ Orientações sobre AIDS* } \\
\hline Familia : & 19 & 86,4 & 48 & 70,6 & 35 & 81,4 & 102 & 76,7 \\
\hline Escola & 17 & 72,3 & 58 & 85 & 35 & 81,4 & 110 & 82,7 \\
\hline \multicolumn{9}{|l|}{ Outros locais } \\
\hline Outras instituições & 2 & 9,1 & 7 & 10,3 & 2 & 4,7 & 11 & 8,3 \\
\hline Amigos & 2 & 9,1 & 4 & 5,9 & 2 & 4,7 & 8 & 6,0 \\
\hline $\begin{array}{l}\text { Necessidade de receber } \\
\text { orientações sobre Aids }\end{array}$ & 7 & 31,8 & 32 & 47,1 & 26 & 60,5 & 65 & 48,9 \\
\hline
\end{tabular}

*As respostas negativas foram omitidas da tabela. Os adolescentes podiam escolher mais de uma resposta. 


\section{DISCUSSÃO E CONCL USÕES}

Ao introduzir a discussão, será preciso destacar que privilegiamos, neste estudo, a análise estratificada, levando-se em conta que as manifestações do processo saúde-doença e, portanto, das necessidades humanas nao são homogêneas, alertadas pelo "perigo de trabalhar com indicadores de ponto médio, pois estes mascaram - e às vezes o fazem perfeitamente - o impacto diferencial da crise" (CAMPANA, 1997, p. 163). De outro lado, mesmo recorrendo ao emprego das leis estatísticas para o confronto dos dados, muitas vezes foi necessário além do que elas evidenciavam, para fazer a leitura possível de tendências, nem sempre detectáveis pelos métodos empregados, optando assim por compatibilizar a análise estatística com o que a realidade estudada tende a evidenciar.

Assim, foi possível reconhecer, primeiramente que, apesar de viverem num espaço periférico do Município de São Paulo - o da Raposo Tavares - as famílias dos adolescentes estudados guardavam características desiguais de reproducão social. Estavam desigualmente incluídos - ou excluídos - numa "sociedade dual, entre aqueles que se encontram plenamente incluídos (...) e os demais, os precariamente incluídos e os excluidos (POCHMANN, 1999, p.22). Uma pequena parcela congregava famílias protegidas da expansão da precarização do trabalho e da inacessibilidade ao uso do espaço geo-social (plenamente incluídos); a grande maioria concentrava, alternadamente, padrões adequados/inadequados de inserção no trabalho e na vida, absorvendo intensamente as contradições (crises) que se impõem na reprodução social da sociedade capitalista contemporânea (precariamente incluídos). Um terço, porém, congregando famílias atingidas pelos efeitos perversos da revolução no e do trabalho, vivia sob os padrões da exclusão social (excluídos sociais) (QUEIROZ \& SALUM, 1997).

O tratamento das necessidades de saúde de adolescentes, vistas a partir do critério da inserção social das suas famílias e tomando por referência as agências e espaços de socialização, permite, de uma maneira geral, complementar a construção de projetos de intervenção e de ações de instrumentalização da inteligência popular para a concretização do monitoramento estratégico em saúde (BREILH, 1994) uma vez que faz a leitura das especifidades de um determinado espaço geosocial. Ademais, a possibilidade de, empiricamente, comprovar a existência de diferentes necessidades de acordo com as diversas formas de reprodução social das famílias, particularmente, ajuda a desmistificar modelos cristalizados de adolescentes que tratam de retirar de cena as várias faces dos vários adolescentes pobres, desmascarando uma racionalidade que reduz as diferenças (SOARES, 1997).

O acolhimento/proteção na família, na escola e no bairro foi, inequivocamente, a necessidade que mais se evidenciou: expressa nas opiniões dos adolescentes, no confronto entre a valorização do afeto e da vivência de situações adversas, mas especialmente a partir do ressentimento com as situações de violência física ou verbal ou da carência de convívio com os familiares, ocupou o depoimento não só daqueles que vivem a possibilidade da inclusão como dos que vivem na exclusão social. Decodificado na necessidade de amor, diálogo na família e com os pais e no variado acesso ao lazer, preencheu a voz do adolescente a partir da vivência no espaço da inclusão. Para os que iam se construindo no espaço da exclusão, traduziu-se nas manifestações de necessidade de amigos, da presença dos familiares no espaço doméstico e da convivência mais freqüente de um parceiro para compartilhar suas experiências. O acolhimento/proteção se revelou como necessidade também na escola, e no bairro: foi positivado na contraposição entre o valor que atribuem aos elementos imediatamente mais concernentes ao processo de socialização (amizades e lazer) e a denúncia da precariedade dos equipamentos e recursos educacionais e de situações de violência. É preciso reconhecer, no entanto, que também nesses espaços, o acolhimento/proteção se expressou como necessidade especialmente à medida que a exclusão social integrava a vida do adolescente e, na escola, em oposição ao elemento mais nuclear da instituição de ensino. Finalmente, a freqüência com que os adolescentes de quaisquer grupos se manifestaram acerca da necessidade de orientação, seja sobre drogas, sexualidade ou Aids ${ }^{12}$, não poderia deixar de ser avaliada, em última análise, como mais uma das vulnerabilidades que traduziriam a necessidade de acolhimento/proteção.

A violência constitui problema vivenciado, com freqüência, pelos adolescentes ${ }^{13}$ que so-

12 Outros estudos reiteram a importância que os jovens atribuem aos programas educativos na escola. Veja-se, por exemplo, trabalho de KNUNIK (1990).

13 Os estudos sócio-demográficos em nosso meio indicam uma prevalência importante de agressão física contra crianças e adolescentes (20\%), sendo que a esmagadora maioria dos agressores são parentes e conhecidos (80\%) (PNAD/IBGE, 1989 
frem as conseqüências tanto da violência cultural interpessoal como da violência estrutural (MINAYO \& ASSIS, 1994) interrelacionadas que estão: de fato, SANTOS (1999), em estudo realizado com escolares de $\mathrm{l}^{\mathrm{a}} \mathrm{e} 2^{\mathrm{a}}$ séries do $1^{\circ}$ grau de escola periférica, já observara diversidade na manifestação da violência física doméstica, intensificada entre os excluídos sociais relacionada sobretudo com os padrões de relação intra-familiar e com a singularidade dos envolvidos no ato violento. Nossos resultados são também indicativos de que o âmbito da exclusão social vulnerabiliza os adolescentes à situações de violência, nutrindo a visão da preponderância dos determinantes estruturais, muito embora os especialistas no assunto tenham enfatizado que permeando "todas as classes sociais como violência de natureza interpessoal (...) [esteja vinculada ao] (...) abuso do poder disciplinador e coercitivo dos pais ou responsáveis (GUERRA, 1998, p. 32)".

Essas considerações encontram ressonância no destaque dado pelos excluídos à importância da presença de um membro da família e, de outro lado, à manifestação, entre os incluídos, de que o espaço doméstico, provavelmente adequado, preenche suas aspirações. Permitem apontar elementos não somente da função geral da família como espaço social concreto, através do qual os diferentes setores sociais conseguem sua sobrevivência e reprodução (CERVINI \& BURGER, 1991); indicam especificidades que se referem à satisfação de necessidades fundamentais da criança e do adolescente que têm sua possibilidade inicial de acolhimento/proteção no âmbito familiarjá que a família constitui "a esfera íntima da existência, o local exclusivo onde se pode exprimir a própria emoção e agregar-se aos outros (...) o local enfim onde se pode desfrutar a sensação de pertencer" (HELLER, 1987, p. 10).

Mas reiteram também o sentido da escola para o adolescente. Apesar da escola como agencia de socialização encarregada da educação e integração da criança e do adolescente na sociedade - estar vendo crescer suas dificuldades em desempenhar seu papel, especialmente devido à degradação do sistema público escolar, ela constitui, ainda, para os adolescentes um ponto de encontro (ADORNO, 1991). E, não podemos negar, as informações aqui sistematizadas mostram como o espaço escolar constitui espaço de acolhimento para os adolescentes, especialmente para os que vivem na exclusão social. Notadamente, porém, a escola pública a que este estudo se refere tem se distanciado da função socializadora porque, de um lado, estranha o comportamento do adolescente, afastando-o (ADORNO, 1991), e, de outro, é alvo de ceticismo uma vez que há um conflito claro entre o que a escolaridade pode trazer e o que a realidade, de fato, traz (SPOSITO, 1994). A menção mais intensificada entre os adolescentes em todos os grupos de que a violência constituiria um aspecto adverso do espaço escolar encontra sintonia com o alerta de FUKUI (1992) de que a vivência no cotidiano escolar tem sido pautada por conflitos e disputas que vão da agressividade à violência propriamente dita ${ }^{14}$.

A bibliografia mostra que a violência vista como um conflito social que se repete tanto nas mudanças de padrões culturais, quanto em altas taxas de morbi-mortalidade - tem estado relacionada com altos índices de homicídios em jovens de 15-19 anos, no município de São Paulo (MINAYO \& ASSIS, 1994). A análise da transição epidemiológica para a violência relativa à mortalidade de jovens em São Paulo mostra que estes estão morrendo mais por acidentes de trânsito e homicídios (VERMELHO \& JORGE, 1996). Na região do D. A. Raposo Tavares, no ano de 1997 a maior parte das mortes por causas externas entre adolescentes foi devida a ferimento com arma de fogo ou objeto contundente (FUNDAÇÃO SEADE, 1997).

A região prescinde de espaços de lazer e as iniciativas existentes no sentido de melhorar 0 lazer no bairro se restringem ao projeto Nova Escolar que se limitou a abrir as quadras, nos finais de semana, de algumas escolas da região pesquisada. De acordo com jornais da região, as praças e parques, que seriam outra opção de lazer para os adolescentes, são poucas e estão abandonadas, sem receber qualquer tipo de manutenção. De outro lado, o D. A. Raposo Tavares só tem um Centro de Juventude - única alternativa regular para atividades esportivas e de lazer - que estaria atendendo apenas a 2,3\% da demanda de crianças e adolescentes (SPOSATI, 1996).

Consideradas também as queixas quanto à: falta de oportunidades e espaços de lazer; convivência com as drogas e outras dificuldades em tornar o tempo de lazer agradável e construtivo; trata-se de propor medidas que operem tanto no âmbito macrossocial - estimulando políticas sociais públicas que fomentem a igualdade social e

14 Para os debatedores do simpósio “A produção da exclusão social: violência e educação” - um dos debates que fizeram parte da 6 ${ }^{\text {a }}$ Conferência Brasileira de Educação, realizada em 1991 (SEVERINO et al. 1991), de fato, a exclusão social se encontra na base dos problemas de violência na e contra a escola. 
a melhoria da qualidade de vida - quanto no âmbito microssocial - permitindo ações que instrumentalizem os jovens a exercitar a busca de uma existência social participativa e crítica em relação aos problemas que enfrentam e às necessidades que percebem durante o processo de socialização (SOARES \& JACOBI, 2000).

Agradecimentos: Agradecemos: à FAPESP e à Pró-reitoria de Pesquisa da USP, pelo apoio fi- nanceiro; às Secretarias Municipal e Estadual de Educação e ao Centro de Proteção ao Adolescente Educandário Dom Duarte, pela per missão para a pesquisa; ao Prof. Ruy D. Antunes e Fernão D. de Lima, pelo apoio estatístico; às Profas. Dras. Vilma Machado de Queiroz e Maria Josefina Leuba Salum, autoras do percurso metodológico aqui empreendido, pela retaguarda oferecida, e ao Prof. Dr. Paulo Fortes, por sugestões de caráter ético.

\begin{abstract}
This is an epidemiological descriptive study which has lhe objective of characterizing lhe health needs of adolescente who tive in a social vulnerable neighborhood of lhe city of São Paulo (Raposo Tavares). A questionnaire and a form were utilized to collect data Dom a sample of 133 adolescente from lhe 12 public schools and lhe Youth Center of lhe community. Data Dom social reproduction indicators were organized to socially classify the adolescents' families in three social groups. The results indicated that $16.5 \%$ of them were in a socially included group, $51.1 \%$, in a precariously included group and, finally, $2.3 \%$ of the adolescents were considered being in a socially excluded group. There were some significant quantitative and qualitative differences in the health needs felt by the adolescents when they refer to family, school and neighborhood. To satisfy these needs, it is necessary to improve social public policies and to empower youngsters to exercise their rights in order to guarantee care and protection during their socialization processes.
\end{abstract}

Key-words: adolescents; health needs; school; family; neighborhood; homogenous social groups.

\section{REFERÊNCIAS BIBLIOGRÁFICAS}

ADORNIO, S. A socialização incompleta: os jovens delinqüentes expulsos da escola. Cad. Pesq., 79: 77-80, 1991.

AMARO, C.M. et al. Papel da educação na ação preventiva ao abuso de drogas e às DST/Aids. São Paulo: EDE, Série Idéias, 29, 1996.

AYRES, J. R. d. C. M. O jovem que buscamos e o encontro que queremos ser: a vulnerabilidade como eixo de avaliações de ações preventivas do abuso de drogas, DST e AIDS entre crianças e adolescentes. Série Idéias/Fundação para o Desenvolvimento da Educação, 29: 15-25, 1996.

AYRES, J. R. C. M.; JUNIOR, I. E Saúde do adolescente. In: SCHRAIBER, L. B. etalli. (Org.). Saúde do adulto: programas e ações na unidade básica São Paulo: Hucitec, 1996, p.6685.

BREILH, J.; GRANDA, E. Investigação da saúde na sociedade: guia pedagógico sobre um novo enfoque do método epidemiológico. São Paulo: Cortez, Instituto de Saúde/Abrasco, 1989.

BREILH, J. Nuevos conceptos y técnicas de investigación: guia pedagógica para un taller de metodología. Quito: CEAS, 1994, Parte II, cap. 7, p.203-22.
CAMPANA, A. Em busca da definição de pautas atuais para o delineamento de estudos sobre condições de vida e saúde. In: BARATA, R.B. (Org.). Condições de vida e situação em saúde. Rio de Janeiro: ABRASCO, 1997 (Cap. 5, p. 11 5-65).

CERVINI, R.; BURGER, F. O menino trabalhador no Brasil urbano dos anos 80. In: FAUSTO, A.; CERVINI, R. (Org.). O trabaIho e a rua - Crianças e adolescentes no Brasil urbano dos anos 80, São Paulo: Cortez, 1991 (Cap. 1, p. 17-46).

COMISSÃO Nacional de População e Desenvolvimento. Jovens acontecendo na trilha das políticas públicas. Brasília, 1998 (2v).

FACCHINI, L. A. Teoria. In: FACCHINI, L. A. Trabalho materno e ganho de peso infantil. Pelotas: UFPel, 1995, cap. 2.

FUKUI, L. A produção da exclusão social: violência e educação. In: SEVERINO, A. J. et al. Sociedade Civil eEducação. Campinas: Papirus, 1992. (Coletanea CBE).

FUNDAÇÃ̃O IBGE. Contagem da população. São Paulo, 1996. Disponível na Internet [on tine]: <http://www.sidra.ibge.gov.br/cgi-bin/ prtabl $>15 /$ jun/1 998.

FUNDAÇÃO SEADE. Crianças e adolescentes: pesquisa das condições de vida na Região Metropolitana de São Paulo. São Paulo: SEADE, 1993. 
FUNDAÇÃO SEADE. Movimento do Registro Civil Mortalidade por causas externas. São Paulo: SEADE, 1997.

GUERRA, V. N. A. Violência de pais contra $f$ Ihos: a tragédia revisitada. 3. ed. São Paulo: Cortez, 1998.

HELLER, A. A concepção de família no estado de bemestar social. Serv. Social \& Soe., 24: 532, 1987.

KNIJNIK, J. et al. Necessidades educativas de jovens sobre doenças sexualmente transmissíveis. Anais bras Dermatol, 65: 289-92, 1990.

LAURELL, A. C. Para o estudo da saúde na sua relação com o processo de produção. In: LAURELL, A. C.; NORIEGA, M. Processo de produção e saúde: trabalho e desgaste operário. São Paulo: HUCITEC, 1989. cap. 3, p.99-144.

MADEIRA, F. R. Os jovens e as mudanças estruturais na década de 70: questionando pressupostos e sugerindo pistas. Cad. Pesq., 58: 1548, 1986.

MINAYO, M.C.d.S.; ASSIS, S.G. Saúde e violência na infância e na adolescência. Jornal de Pediatria, 70 (5): 263-6, 1994.

MUUSS, R. Teorias da adolescência. Belo Horizonte: Interlivros, 1976.

POCHMANN, M. O trabalho sob fogo cruzado: exclusão, emprego e precarização no final do século. São Paulo: Contexto, 1999. (Coleção Economia).

QUEIROZ, V. M.; SALUM, M. J. L. Operacionalizando o conceito de coletivo na releitura da categoria da reprodução social. Comunicação Coordenada apresentada ao V Congresso Brasileiro de Saúde Coletiva, Lindóia, 1997.

SALUM, M. J. L. A construção de perfs epidemiológicos e a responsabilidade da universidade pública na luta pela saúde como direito social. Relatório final de pesquisa encaminhado à FAPESP, São Paulo, 2000, 2v.

SANTOS, E. V. d. Para além do desfecho: a violência fisica doméstica contra o escolar como processo social e como questão da saúde coletiva. [Tese (Doutorado) - Escola de Enfermagem, Universidade de São Paulo, 1999].
SCHRAIBER, L.B.; MENDES-GONÇALVES, R.B. Necessidades de saúde e atenção primária. In: SCHRAIBER, L.B. et alii (Org.). Saúde do adulto: programas e ações na unidade básica São Paulo: Hucitec, 1996, p.29-47.

SEVERINO, A. J. et al. Sociedade Civil e Educação. Campinas: Papirus, 1992. (Coletânea CBE).

SOARES, C. B. Adolescentes, drogas e AIDS: avaliando aprevenção e levantando necessidades. [Tese (Doutorado) - Faculdade de Educação, Universidade de São Paulo, 1997].

SOARES, C. B.; ÁVILA, L. K. d.; SALVETTI, M. d. G. Vulnerabilidade de adolescentes no SILOS Butantã. Saúde e Sociedade, 7 (2): 63-82, 1998.

SOARES, C. B. ; JACOBI, P. R. Adolescentes, drogas e AIDS: avaliação de um programa de prevenção escolar. Cad. Pesq., 109: 213-37, 2000.

SPOSATI, A. (Coord.). Mapa da exclusão/inclusão social da Cidade de São Paulo, São Paulo: EDUC, 1996.

SPOSATI, A. (Org.). Que cidade é esta? Mapa da exclusão/inclusão da Cidade de São Paulo, Região Oeste 1. Núcleo de Estudos e Pesquisas sobre Seguridade e Assistência Social PUC-SP, s/d.

SPOSITO, M. A sociabilidade juvenil e a rua: novos conflitos e ação coletiva na cidade. Tempo social. Rev Sociol. USP, 5 (1-2): 161-78, 1994.

STOTZ, E. N. Necessidades de saúde: mediações de um conceito (Contribuição das Ciências Sociais para a fundamentação teóricometodológica de conceitos operacionais da era de Planejamento em saúde. 513, p. 2v. Tese (Doutoramento) Escola Nacional de Saúde Pública, Rio de Janeiro, 1991.

VERMELHO, L. L.; JORGE, M. H. Rd. M. Mortalidade de jovens: análise do período de 1930 a 1991 (a transição epidemiológica para a violência). Rev. SaúdePúbl., 30 (4): 319-31, 1996.

WITT, A. Metodologia de pesquisa. São Paulo: ResenhaTributária, 1973.

ZALUAR, A. Da revolta ao crime S. A. São Paulo: Moderna, 1996. 